\title{
Online Learning Engagement Among Music Education Students: A Case Study of Zhengzhou Normal University, China
}

\author{
Lian Jue1 iD, Pan Kok Chang2* \\ ${ }^{1}$ Faculty of Creative Arts, University of Malaya (UM), 50604, Kuala Lumpur, Malaysia. \\ Email:371290646@qq.com \\ ${ }^{2}$ Faculty of Creative Arts, University of Malaya (UM), 50603, Kuala Lumpur, Malaysia. \\ Email: pankc@um.edu.my
}

\section{CORRESPONDING \\ AUTHOR (*): \\ Pan Kok Chang \\ (pankc@um.edu.my)}

\section{KEYWORDS:}

Online teaching

Online learning

Learning engagement

Learning motivation

Music education

undergraduates

\section{CITATION:}

Lian Jue \& Pan, K. C. (2022). Online Learning Engagement Among Music Education Students: A Case Study of Zhengzhou Normal University, China. Malaysian Journal of Social Sciences and Humanities (MJSSH), 7(2), e001279.

https://doi.org/10.47405/mjssh.v7i2.1279

\begin{abstract}
Due to the outbreak of the COVID-19, online teaching and learning with the integration of "Internet + Smart" technology has emerged as significant ways for higher education at home and abroad. In the context of the epidemic, online teaching has become one of "the new normal". The essay is aimed at exploring the factors in music education undergraduates' online learning engagement in blended learning and consequently improving their online learning engagement. A survey of the learning engagement of undergraduate music education students who conducted online learning in 2020 at Zhengzhou Normal University in Henan Province, China. It is found that college students, during the epidemic, had a moderate to high level of learning engagement, a high level of behavioral engagement, and a low level of cognitive engagement. The level of learning engagement varies with gender, grade, place of residence or equipment. Among those factors, student individual factors are more remarkable, compared with external ones. Motivation has enormous explanatory power, so triggering and maintaining motivation is a crucial way to improve students' engagement in online learning. Based on the findings of the study, the author provides suggestions as to how to improve the online learning engagement of music education undergraduates.
\end{abstract}

Contribution/Originality: This study analyses the level of engagement with learning in the online classroom of contemporary music education undergraduates from the perspective of a questionnaire administered to students, taking into account the fact that many times face-toface lessons are not possible due to the current covid-19. The comparison is combined with the current classroom situation and will hopefully contribute to the improvement of motivation and engagement levels of music education undergraduates.

\section{Introduction}

In 2020, amid the pandemic, online teaching programs were launched worldwide to respond to the COVID-19. China's Ministry of Education issued a notice, on 29 January 
2020, of postponing the spring semester and required schools at all levels to actively employ online platforms and information-based teaching methods (Shi Xue \& Yang Xiaojuan, 2020; Xu Kai \& Li Yannan, 2021). The development of information technology in the educational field has been greatly promoted, together with artificial intelligence, adaptive learning, and learning analytics in China. Chinese universities tend to adopt blended learning, and it has become the new norm of online learning in the context of the "Internet+" (Wang Meng, 2019; He Lin et al., 2020).

Undergraduates of Music Education used to attend class in a classroom or a piano room, and face-to-face communicate and interact with their teachers. However, now under the COVID-19 prevention and control, students are required to study at home, and they meet the unprecedented challenge of the lack of physical learning environment and instant communication with teachers and other students (Song Lingqing, $\mathrm{Xu}$ Lin \& $\mathrm{Li}$ Yaxuan, 2020). Whether students can devote themselves to online learning at home is a matter of concern. What influences their engagement in learning and what the influences also arouse people's interest.

The answers to those questions are considerably helpful for relevant parties to understand students' online learning situation. After understanding the situation, for college students, they can adjust their learning status; for parents, they can improve the learning environment to a large extent and offer psychological support to their children; for college students, they need to optimize the online learning process and enhance their learning efficiency during home study sessions (Blundell et al., 2020; Heo et al., 2021). It also provides a reference for the innovation of mixed teaching models for music education undergraduates after they return to school and resume their studies.

\section{Background}

The minor courses for majors in music mainly include piano performance, vocal singing and other instrumental music performance. Generally speaking, those hands-on and skill-based courses are taught face-to-face. During the pandemic, a significant number of music teachers chose to use WeChat, QQ, and Dingding to establish "one-to-one" connections for lessons; besides, not a few teachers tended to use the "Practice Together", an app, to deliver "one-to-one" or "one-to-two" lessons (Song Lingqing et al., 2020; Yuan Zhihong, 2021). However, the existing online teaching software cannot fully satisfy the needs of both teachers and students, including high quality sound reproduction, demonstration of key touch and sound synchronization. Therefore, music teachers began to think about and experiment on new teaching models.

The traditional class of those minors focuses heavily on face-to-face teaching of performance and singing techniques, and teachers tend to spend a large amount of time demonstrating and explaining (Adnan \& Anwar, 2020). Now, when conducting online instruction, teachers can shift the focus from singing and performance techniques to the analysis of works and musical art.

The theoretical courses mainly include music history, music tracks appreciation and music education psychology. The teachers of those courses use multiple online platforms for blended teaching. They use those platform mainly for check-in, live or recorded teaching, assigning tasks, sharing teaching materials, assessments and posting notifications. The author believes that the "learning platform + social platform" blended 
teaching cloud classroom has really brought innovation to the major theoretical courses of music education.

The major practical classes consist of music pedagogy, sight-singing and ear training, and choral singing and conducting. The cloud classroom mode is applied to them as well, coupled with multiple online platforms (Song Lingqing et al., 2020). In contrast, the practical courses attach importance to practicality; the teacher's demonstration, case analysis and students' practice take up a large proportion of class time, so the majority of tutors choose the " recording + live" mode for online teaching.

However, the online mode are not suitable for all courses, say large-scale practical classes. To be specific, instrumental ensembles cannot yet be effectively taught online with the current technology.

Based on this, this study attempts to understand the current state of online learning engagement among music education undergraduates in a blended learning environment from three perspectives: cognitive, behavioral, and emotional engagement.Therefore, this study attempts to address the following three questions:

i. What is the current status of music education university students' engagement in blended learning?

ii. What are the factors influencing online learning engagement of music education undergraduates in blended learning?

iii. How to improve the level of online learning engagement of music education undergraduates in blended learning?

\section{Literature Review}

\subsection{Blended Learning}

Using the Internet to popularize and promote distance education dates back to the 1990s.In the United States, for example, the online teaching platform called Blackboard LLC ("Bb Platform") was born in 1997 under the Clinton administration's initiative to promote the use of the Internet and computer technology for the educational development. After several years of trial and improvement, the Bb platform was officially introduced to all primary and secondary schools in the United States in 2005. Its main function is to set up a platform for teachers and students to share teaching resources via the Internet.

The current research on blended learning focuses on the definition of the concept of blended learning, case studies and platform construction.

In terms of definition, according to He Kehang (2004), the so-called Blended Learning is to combine the advantages of traditional learning methods (supporting students' independent learning and self-management, motivating students to explore and innovate) with those of e-learning (i.e. digital or networked learning). Shi Xiaocen (2016) offers valuable insights into blended learning in China by exploring both the positive and negative aspects of blended learning in the United States. Yin Rui and Xu Hanyun (2017) explains that the classroom design for blended teaching and learning by the ADDIE education model can provide guidelines for the integration of theory and practice of blended teaching and learning reform. According to Song Lingqing et al. (2020), blended learning is the systematic and scientific organic combination of traditional teaching 
methods, including classroom education, classroom listening, experimental research, field trips, observational learning, and practical training learning, with information technology.

In terms of the application of blended learning, research has been conducted at all levels from elementary school to university, and in a variety of disciplines and online platforms. For instance, Ye Lixia (2020) launched the exploration of blended teaching of linear algebra based on Learning Pass and Dingding. Sun and Gao (2020) also explored the reform of blended teaching mode based on Rain Classroom in the context of "Internet +".

\subsection{Definition of learning engagement}

Astin (1984) considers learning engagement to be the sum of the mental and physical effort that students put into their learning activities. In 1985, his early research on student engagement initially assumed that "learning engagement" was composed of physical and mental energy, was situation-specific and included both quantitative and qualitative components. Newmann (1992) defines learning engagement as "the mental investment and effort of students directed towards learning, understanding and mastering knowledge and skills". Skinner, Wellborn and Connell (1990) argue that student engagement in learning refers to the behavior, effort, persistence and the positive emotions that accompany this process during school life. Schaufeli (2002) identifies learning engagement as a positive, fulfilling state of mind associated with learning that includes three dimensions of energy, dedication and focus. Fredricks et al. (2004) takes an alternative approach to defining the concept of learning engagement, with Fredricks et al. (2004) and others suggesting that learning engagement includes three dimensions: behavioral, emotional and cognitive (Fredricks et al., 2004; Woo \& Reeves, 2007; Wang, 2008; Chen Xiaoke, 2016). According to Kuh (2004), "engagement in learning" is a key factor in evaluating teaching and learning, and refers to the amount of time and effort that learners put into effective learning, and the amount of effort they put into effective educational practices. According to Chinese scholar Sun Hongmei et al. (2011), learning engagement refers to the degree of behavioral involvement, the quality of emotional experience and the level of cognitive strategies used by students in performing learning activities, and it includes three dimensions: behavioral engagement, emotional engagement and cognitive engagement, which is a serious psychological investment in students' academic performance.

As Fredricks et al. (2004) three-dimensional structure of learning engagement is crossculturally stable and more appropriate to the learning environment of the online learning space in this study, learning engagement is considered in this study to be defined as the behavioral, cognitive and emotional engagement generated by learners as they engage in online learning activities in an online learning environment.

\subsection{Study of learning engagement under blended learning}

The essence of blended learning is to rethink and redesign the relationship between teaching and learning, and to adjust the structures and methods of teaching and learning (Wang Meng, 2019). By integrating online teaching and traditional classroom teaching, students can be provided with more opportunities for peer interaction, independent learning and self-management, and can effectively improve their ability to employ appropriate strategies for in-depth learning. 
Based on the characteristics of blended learning, behavioral engagement focus on student-initiated learning, teacher-student interaction, and group collaboration (Yuan Zhihong, 2021). The researcher argues that in traditional face-to-face teaching, learning activities are confined to the classroom, and it is difficult to meet learners' individual needs, especially as class sizes continue to increase due to the expansion of university enrollment in China. Blended learning allows more flexible course design, multiple channels of course resources, and different forms of learning activities, which can effectively trigger students' active and independent learning (Wang Meng, 2019).

Cognitive engagement consists primarily of strategies for implementing deep learning and self-management (Fredricks, et al., 2004). Thanks to the change in learning environment, more instructional time can be allocated to fulfil the achievement of highlevel cognitive objectives such as application, synthesis, assessment and analysis. A flexible learning approach at the end of the lesson also provides more feedback and communication opportunities for students (Chen, 2017). It is shown that a high level of student self-management and supervision has a positive impact on blended learning as well (Woltering et al., 2009).

Emotional engagement means students' emotional responses to blended instruction, such as enthusiasm, interest, enjoyment and sense of belonging. The advantage of blended instructional design is that it allows for the appropriate use of face-to-face and online environments to offer emotional support to students at the right time. For example, early in the course, an online class makes students feel less anxious and creates more relaxed atmosphere, so students can be more actively engaged in learning. Faceto-face interactions, on the other hand, play a significant part in building up community, group identity, and trust in cooperative learning (Garrison \& Vaughan, 2008).

\section{Methodology}

\subsection{Research participants}

Students majoring in music education started their spring semester of 2020 to 2021 at Zhengzhou Normal University in Henan Province by online learning from home. Zhengzhou Normal University is an undergraduate institution in Henan Province, and its enrollment and school influence are in the middle level of all universities in Henan, so the research results can be fairly typical and regionally representative.

The questionnaires were distributed, from May 24 to June 4, 2021, to all music education undergraduates at Zhengzhou Normal University who were studying online and were completed voluntarily. A total of 336 students were enrolled in four years of music education at Zhengzhou Normal University, and 200 students were randomly selected for the online questionnaire, and 162 questionnaires were collected. Excluding those with incomplete or no committed answers, 136 valid questionnaires were obtained, with an effective rate of $68 \%$. 45 respondents (33\%) were male and $91(67 \%)$ were female. There were 39 (29\%) freshmen, 30 (22\%) sophomores, 42 (31\%) juniors and $25(18 \%)$ seniors.

\subsection{Research Instrument}

In-home online learning is a special form of learning during the COVID-19. Music education university students have distinctive traditional classroom learning habits and 
learning behavior characteristics, but at the same time have the main characteristics of online learning.

This study combines the distance online learning engagement scale developed by Sun and Rueda (2011), the distance student learning engagement evaluation scale by $\mathrm{Li}$ Shuang and Yu Chen (2015), and the college student learning engagement scale by Wang Yashang (2013). In addition, it combines the characteristics of online learning at home to form the online learning engagement questionnaire, including cognitive engagement, behavioral engagement and emotional engagement. The Likert scale was used, with 1 meaning "completely disagree", 2 "not really agree", 3 "not sure", 4 "relatively agree", and 5 "completely disagree". In this study, higher scores indicate higher levels of learning engagement.

After the questionnaire was designed, a pilot test was conducted among the college students, the results were used to revise the questionnaire, in terms of its appropriateness, representativeness and presentation, to ensure that the content of the questionnaire could accurately and comprehensively reflect the current situation of college students' at-home online learning engagement. The internal consistency coefficients (Cronbach's a coefficient) of cognitive engagement, behavioral engagement and emotional engagement were $0.934,0.924$ and 0.930 respectively, and the internal consistency coefficient of learning engagement as a whole was 0.967 , so the reliability of the questionnaire was high.

\subsection{Conceptual and operational definitions}

As Fredricks et al. (2004) three-dimensional structure of learning engagement is crossculturally stable and more suitable for the online learning environment of music education undergraduates in this study, learning engagement is defined in this study as the behavioral, cognitive and emotional engagement that occurs when music education undergraduates engage in online learning activities in an online learning environment.

Behavioral engagement refers to learners' behaviors in participating in learning activities. In this study, the behavioral engagement of music education undergraduates in online learning is considered to include the frequency of music education undergraduates' access to online learning spaces for learning, course learning and the completion status of assignments. Behavioral engagement examines the behavioral performance of music education undergraduates in and out of the classroom as they engage in learning. The five main items include the amount of practice before and after class during the semester's online lessons, active participation in or organization of various music professional activities and competitions, attendance at each online lesson, and completion of assignments.

Emotional engagement refers to the emotional experience of learners as they engage in learning activities. In this study, emotional engagement refers to music education students' attitudes towards the knowledge, resources and environment in the online learning space, as well as their learning experience and sense of belonging to the online learning space when they use it for learning. Emotional engagement examines students' expectations of learning and the emotional responses directed towards subjects such as peers, teachers and school administration in the learning process. The five main items include timely feedback on learning performance with teachers or classmates, 
relationships with classmates and teachers, positive and enthusiastic completion of each assignment given by the teacher, and working harder to meet the teacher's expectations. Cognitive engagement refers to the learning strategies, learning methods and learning styles that learners use to complete their learning. The cognitive engagement in this study mainly refers to the learning styles, learning readiness and information processing strategies of music education undergraduates when studying online. Cognitive engagement examines the learning strategies and learning styles of music education undergraduates, as well as their perceptions of learning achievement and the value of learning. This includes active discussion and collaboration with other students in and out of the classes, taking the initiative to ask questions and express their views in class, discussing their career plans and ideas with teachers, and discussing their outlook on life with teachers in five items.

\section{Results}

\subsection{Attitudes towards online teaching}

In the first part of the personal context there are questions about the attitudes of music education undergraduates towards online courses and their opinions on the length of online courses. The overall attitudes can be summarized as accepting, neutral and not accepting. The length of the course represents the length of time that music education students are dedicated to the online course and the length of time they are engaged in the online course. The results of the questionnaire on attitudes towards online teaching are shown in Table 1.

Table 1: The attitudes of music education undergraduates towards online teaching

\begin{tabular}{llll}
\hline Attitude & Accepted & Neutral & Not Accepted \\
\hline Population(percentage) & $66(48.6 \%)$ & $58(42.6 \%)$ & $12(8.8 \%)$ \\
Duration of a single class & $45 \mathrm{~min}$. & $30 \mathrm{~min}$. & $20 \mathrm{~min}$. \\
Population(percentage) & $68(50 \%)$ & $62(45.6 \%)$ & $6(4.4 \%)$ \\
\hline
\end{tabular}

The acceptance and recognition of online teaching is relatively high among today's music education undergraduates, of these, $48.6 \%$ said they were very receptive to online courses and $42.6 \%$ were neutral, or a total of $91.2 \%$ of students claiming they like or are willing to accept this new model, and merely $8.33 \%$ stating they are uncomfortable with it. $95.6 \%$ of the students said it was appropriate to limit the duration of a single session to 30 to 45 minutes. The results illustrate that the music education university students generally have maturity, and online teaching is suitable for them. This result also shows that the majority of music education undergraduates are engaged in a single lesson for around 30-45 minutes.

\subsection{Current status of online learning engagement of music education undergraduates}

The online learning engagement of music education undergraduates under COVID-19 prevention and control is presented in Table 2 . From the results, it can be seen that the online learning engagement level of majors in music education is moderate and even high, with behavioral engagement being the highest, emotional engagement the second and cognitive engagement the lowest. It reflects that music education undergraduates at home have more online learning behaviors, but they have not yet developed effective online learning strategies and learning methods; their ability to transform explicit 
external behavioral inputs into effective cognitive strategies and cognitive activities needs to be further improved.

The data on cognitive engagement shows that $36 \%$ of students actively apply their knowledge from this course to new problem solving processes. For problems that they do not understand before or during class, $44 \%$ of students actively seek help from teachers and others, which shows that most students still lack a sense of active problem solving. The percentage of students who were willing to spend more time in class to learn more about the issues discussed in class was $49 \%$. The above data suggest that the current cognitive engagement of music education undergraduates needs to be further improved.

Table 2: Online learning engagement of music education undergraduates

\begin{tabular}{lllll}
\hline & $\begin{array}{l}\text { Minimum } \\
\text { value }\end{array}$ & $\begin{array}{l}\text { Maximum } \\
\text { value }\end{array}$ & Average value & $\begin{array}{l}\text { Standard } \\
\text { deviation }\end{array}$ \\
\hline Cognitive & & & & \\
engagement & 1 & 5 & 3.375 & 0.635 \\
Item1 & 1 & 5 & 3.286 & 0.627 \\
Item2 & 1 & 5 & 4.012 & 0.851 \\
Item3 & 1 & 5 & 3.313 & 0.633 \\
Item4 & 1 & 5 & 3.012 & 0.517 \\
Item5 & 1 & 5.252 & 0.547 \\
Behavioral & & 5 & & \\
engagement & 1 & 5 & 4.013 & 0.653 \\
Item1 & 1 & 5 & 3.868 & 0.581 \\
Item2 & 1 & 5 & 4.362 & 0.897 \\
Item3 & 1 & 5 & 4.035 & 0.668 \\
Item4 & 1 & 5 & 3.627 & 0.522 \\
Item5 & 1 & & 4.173 & 0.597 \\
Emotional & & 5 & & \\
engagement & 1 & 5 & 3.909 & 0.602 \\
Item1 & 1 & 5 & 4.032 & 0.630 \\
Item2 & 1 & 5 & 3.968 & 0.593 \\
Item3 & 1 & 5 & 3.745 & 0.630 \\
Item4 & 1 & 5 & 3.616 & 0.516 \\
Item5 & 1 & - & 4.184 & 0.646 \\
Total & - & & 3.766 & 0.604 \\
\hline
\end{tabular}

The behavioral engagement dimension includes three stages: before, during and after class, i.e. preparation for class, learning and discussion during class, and assignments after class. In the pre-class learning activities, $49 \%$ of the students "always" studied in advance and watched online videos. During the online lesson, $66 \%$ of students listened carefully and took notes, and $52 \%$ of students "always" participated in online discussions. $95 \%$ of students were able to submit their assignments on time. Based on the analysis of the data, it can be seen that students' behavioral engagement before and during class is average, while their behavioral engagement after class is high.

Emotional engagement refers to the emotional response of students to online courses. The data shows that $46 \%$ of students "always" find listening to teachers boring. $73 \%$ of students find their learning in class rewarding. $60 \%$ of students are "always" engaged in the learning process before and during class. $53 \%$ of students were satisfied with their 
learning outcomes. The above data indicate that students are generally well engaged emotionally.

The three dimensions of learning engagement are both relatively independent and influence each other. Cognitive engagement is a prior to behavioral and emotional engagement, and behavioral engagement is a reflection of cognitive and emotional engagement. In turn, behavioral engagement as well as emotional engagement will further enhance the perception of learning engagement. The higher the individual's engagement in a particular dimension, the higher the overall learning engagement will be.

\subsection{Number of students with different levels of learning engagement}

K-Means Cluster Analysis was applied to analyze the overall situation of university students' online learning engagement under COVID-19 prevention and control, and it was classified into high level of engagement, medium level and low level. The distribution of the number of university students at each level of learning engagement is shown in Table 3.

Table 3: Distribution of the number of students with different levels of learning engagement

\begin{tabular}{llll}
\hline & $\begin{array}{l}\text { high level of } \\
\text { engagement }\end{array}$ & $\begin{array}{l}\text { medium level of } \\
\text { engagement }\end{array}$ & $\begin{array}{l}\text { low level of } \\
\text { engagement }\end{array}$ \\
\hline Population(percentage) & $28(20.6 \%)$ & $82(60.3 \%)$ & $26(19.1 \%)$ \\
\hline
\end{tabular}

The results indicate that the largest number of at-home students are at the medium level of engagement, accounting for 60.3\%; the students with high level account for $20.6 \%$ while the students with low level is $19.1 \%$. The online learning engagement showed a normal distribution, and this result was similar to those students' engagement in traditional classroom teaching. To a certain extent, it indicates that music education undergraduates have a relatively stable distribution of learning engagement, both in classroom learning on campus and online learning at home.

\subsection{Analysis of the differences in home online learning commitment among music education undergraduates in different backgrounds}

Analysis of variance (ANOVA) was conducted on the variables of gender and residence, grade level, and IT skills of music education college students. The results are shown in Table 4.

Table 4: Differences in learning engagement dimensions across background conditions of music education undergraduates

\begin{tabular}{llllll}
\hline & $\begin{array}{l}\text { Specific variables } \\
\text { M (SD) }\end{array}$ & $\begin{array}{l}\text { Cognitive } \\
\text { engagement } \\
\text { M (SD) }\end{array}$ & $\begin{array}{l}\text { Behavioral } \\
\text { engagement } \\
\text { M (SD) }\end{array}$ & $\begin{array}{l}\text { Emotional } \\
\text { engagement } \\
\text { M (SD) }\end{array}$ & $\begin{array}{l}\text { Overall } \\
\text { M (SD) }\end{array}$ \\
\hline Gender & Male & $3.759(0.646)$ & $3.932(0.638)$ & $3.894(0.643)$ & $3.861(0.599)$ \\
Year & Female & $3.739(0.577)$ & $4.018(0.565)$ & $3.920(0.571)$ & $3.893(0.522)$ \\
& Freshman & $3.718(0.611)$ & $3.947(0.598)$ & $3.888(0.598)$ & $3.851(0.556)$ \\
& Sophomore & $3.730(0.601)$ & $3.973(0.586)$ & $3.889(0.599)$ & $3.864(0.549)$ \\
& Junior & $3.804(0.602)$ & $4.046(0.605)$ & $3.961(0.608)$ & $3.937(0.557)$ \\
& Senior & $3.948(0.505)$ & $3.979(0.598)$ & $3.909(0.602)$ & $3.976(0.473)$ \\
\hline
\end{tabular}




\begin{tabular}{|c|c|c|c|c|c|}
\hline \multirow[t]{2}{*}{ Residence } & City & $3.814(0.622)$ & $4.029(0.618)$ & $3.937(0.617)$ & $3.926(0.571)$ \\
\hline & Country & $3.717(0.597)$ & $3.962(0.587)$ & $3.897(0.594)$ & $3.859(0.546)$ \\
\hline \multirow[t]{4}{*}{$\begin{array}{l}\text { Equipment } \\
\text { conditions }\end{array}$} & $\begin{array}{l}\text { Internet access, a } \\
\text { computer and a } \\
\text { smartphone }\end{array}$ & $3.534(0.736)$ & $4.031(0.577)$ & $3.957(0.585)$ & $3.936(0.538)$ \\
\hline & $\begin{array}{l}\text { Internet access, no } \\
\text { computer but a } \\
\text { smartphone }\end{array}$ & $3.672(0.631)$ & $3.963(0.568)$ & $3.888(0.577)$ & $3.850(0.524)$ \\
\hline & $\begin{array}{l}\text { No internet, but } \\
\text { plenty of } \\
\text { smartphone data } \\
\text { traffic }\end{array}$ & $3.822(0.587)$ & $3.941(0.650)$ & $3.879(0.649)$ & $3.831(0.599)$ \\
\hline & $\begin{array}{l}\text { No internet and } \\
\text { insufficient } \\
\text { smartphone data } \\
\text { traffic }\end{array}$ & $3.534(0.736)$ & $3.795(0.748)$ & $3.723(0.720)$ & $3.684(0.691)$ \\
\hline Electronic & High & $4.045(0.546)$ & $4.215(0.564)$ & $4.145(0.565)$ & 4.135(0.509) \\
\hline Technology & General & $3.663(0.542)$ & $3.924(0.452)$ & $3.850(0.459)$ & $3.813(0.494)$ \\
\hline Skill & Low & $2.923(0.720)$ & $3.240(0.749)$ & $3.155(0.726)$ & $3.106(0.668)$ \\
\hline
\end{tabular}

The results illustrate that there is a significant difference in the level of online learning engagement between male and female university students. Female subjects have a significantly higher level of learning engagement than male ones, including behavioral engagement and emotional engagement. There is no enormous difference between male and female students in cognitive engagement. Overall, female students show higher learning engagement than male students.

There exists a significant difference in the online learning engagement in terms of years. However, senior music education students showed a small decline in behavioral engagement and emotional engagement compared to junior music education students. In summary, the higher students years are, the higher the level of learning engagement is. As the years increase, the undergraduates become more comfortable with online learning and have a higher level of engagement in learning.

There is a significant difference between urban and rural university students' engagement in online learning. The level of learning engagement of the students from urban areas was considerably higher than that of students from rural areas. Compared with urban university students, rural students' study environment at home is relatively poor and those students suffer more disturbance, for their family are not capable of providing a quiet and independent space for them.

A stable and smooth network is an important factor in studying online at home for students. The hardware devices are mainly desktop computers, laptops, tablets and smartphones, but the Internet need to be accessible to those devices. There is a discrepancy in the investment in online learning under different network conditions. As long as the network is smooth and stable, students' learning engagement is on the high side; otherwise, it is on the low side.

There is also difference in online learning engagement with different information technology skills. The stronger information technology skills students have, the higher level of learning engagement they have. All courses of music education need to be studied online during the COVID-19 period. The numerous learning platforms, applications, software, online learning resources and forms of online learning participation mean the high requirement for the information technology skills of music 
education undergraduates. The undergraduates with strong IT skills are able to adapt to online learning faster and better, while those with lower IT skills require greater time and effort, which affects their level of learning engagement.

\section{Discussion}

This study measured the learning engagement in online learning among music education undergraduates by distributing questionnaires (Liao Youguo, 2011). From the perspective of those students' individual factors and external factors ( $\mathrm{Li} \mathrm{Lu} \mathrm{\&} \mathrm{Li} \mathrm{Minghua,}$ 2020), the study analyzed the current situation of university students' online learning by establishing the relationship between learning engagement and each factor through research data, and further explored the differences in each factor.

The results of this study indicate that there exists variation in the level of engagement in online learning among the respondents. The factors in learning engagement are complex, and the role of each factor varies widely. The teaching behavior of their music teachers can be regarded as one of the key elements in promoting learning, and stimulating and sustaining motivation is an important way to promote online learning engagement among the students.

Differences in the respondents' backgrounds like gender, place of residence, equipment, grade and information technology skills lead to the difference in online learning engagement (Zheng Qinhua\& Xu Junyan, 2020).

Compared to male students, female students have a relatively higher level of self-control and are willing to comply with school rules and teachers' requirements during the pandemic, so they have a higher level of engagement in learning. This result is consistent with previous research on university students' learning engagement regarding gender differences. Guo Fengru (2019) found that gender was a predictor variable of learning engagement and that there were significant differences between male and female students and between Latin American and African American students.

Compared to those with low grades, the subjects with high grades have higher level of learning engagement. As the year increases, their adaptability is gradually improving and their learning goals are becoming clearer. Therefore, the higher the years are, the higher the learning engagement of the students. This result is also similar to that of a previous study by Chinese scholar Lian Rong.

Compared to those living in rural areas, the respondents with urban background have better facilities and Internet, so their level of learning engagement is relatively higher. The reason for this may lie in the fact that there are real differences between urban and rural environments in China, leading to differences in the training of music education undergraduates brought about by their place of residence.

The subjects who possess high information technology skills better adapt to online learning, encounter fewer technical barriers during the learning process, so they have relatively higher level of learning engagement.

When conducting online teaching, the teachers of music education should fully recognize the above differences, and design appropriate activities to improve the students' online learning engagement. In addition, the teachers should give full consideration to the low 
level of engagement in online learning caused by poor living conditions, inadequate facilities and poor information technology skills. Teachers should also take account of the students' individualized needs, create positive learning atmosphere and environment and improve their online learning performance.

\section{Suggestions}

To better improve the level of engagement in online learning and optimize learning outcomes for music education undergraduates, some suggestions are made regarding the findings of this study.

Firstly, the government needs to provide comprehensive network equipment support and quality learning resources for university students to study online. It is recommended that the university increase its investment in IT infrastructure and provide full 5G network coverage and corresponding learning platform support in different learning scenarios such as classrooms, laboratories, libraries and computer rooms, so that online learning can develop from an emergency state to a normal state and provide environmental support for teaching reform and teaching mode innovation after the epidemic.

Also, the government should provide better online learning venues for some university students living in rural areas so that they can study online in a timely manner and improve their engagement in online learning.

In addition, it is suggested that the design and development of the online teaching platform should improve the ease of use of the design of the online teaching platform for university students in terms of the ease of operation, recognition, compatibility and artistry of the interface design.

Finally, university teachers should give continuous attention, strong support and timely feedback to the development of online courses, so that music education undergraduates can maintain a strong sense of social presence and learning achievement, and increase their motivation and level of engagement in learning.

This study attempts to conduct a more comprehensive exploration of the factors that influence online learning engagement among music education undergraduates, but due to time and effort constraints, it is not possible to achieve a comprehensive analysis of the factors examined. It is hoped that future research will provide a more comprehensive discussion and analysis of the factors influencing online learning engagement among music education undergraduates.

For future research, the following are possible considerations: (1) differences in university online learning environments can affect the actual effectiveness of students' online learning; (2) further research is needed to gain a deeper understanding of the specific role of learning engagement; (3) it can provide a useful reference for researchers at other institutions or in different countries; (4) it is possible to explore university administrators' and teachers' perceptions of online learning and to compare them with students' engagement and performance. 


\section{Conclusion}

Overall, behavioral engagement scores for music education undergraduates were higher than cognitive and emotional engagement, both from a gender perspective and a year perspective. Of the three dimensions of learning engagement, behavioral engagement is an observable and explicit indicator that can reflect students' learning engagement. Cognitive and emotional engagement are implicit indicators that are not easily observed but are closely related to effective student engagement.

The reason may be that the subjects have more explicit learning behaviors in order to complete the tasks assigned by teachers. However, due to the teacher-student separation and lack of effective guidance, face-to-face communication and peer-to-peer inspiration, the students are less competent and less cognitively engaged in effectively employing strategies and having reflective learning.

This study found that there was an impact on the level of engagement in online learning for music education undergraduates in terms of gender, year, residence, equipment and electronic technology.Gender and year are personal factors that cannot be changed, while other external factors, such as environment and equipment, are most influential in affecting the online learning engagement of music education students.

\section{Acknowledgement}

The subject of this paper was extracted from a doctoral thesis submitted to University of Malaya, Kuala Lumpur.

\section{Funding}

This study received no funding.

\section{Conflict of Interests}

The authors declare no conflict of interest in this study.

\section{References}

Adnan, M., \& Anwar, K. (2020). Online learning amid the COVID-19 pandemic: Students perspectives. Journal of Pedagogical Research, 1(2), 45-51. https://doi.org/10.33902/jpsp.2020261309

Astin, A. (1984). Student involvement: A developmental theory for higher education. Journal of College Student Personnel. https://doi.org/chawkinson.pbworks.com

Blundell, G. E., Castañeda, D. A., \& Lee, J. (2020). A Multi-Institutional Study of Factors Influencing Faculty Satisfaction with Online Teaching and Learning. Online Learning, 24(4). https://doi.org/10.24059/olj.v24i4.2175

Chen Xiaoke. (2016). Correlations between Interpersonal Relation, Social Support and Learning Well-Being of Undergraduates. Advances in Psychology, 06(04), 384-390. https://doi.org/10.12677/ap.2016.64050 
Chen, I-Shuo. (2017). Computer self-efficacy, learning performance, and the mediating role of learning engagement. Computers in Human Behavior, 72, 362-370. https://doi.org/10.1016/j.chb.2017.02.059

Fredricks, J. A., Blumenfeld, P. C., \& Paris, A. H. (2004). School Engagement: Potential of the Concept. State of the Evidence. Review of Educational Research, 74(1), 59-109. https://doi.org/10.3102/00346543074001059

Garrison, D. R., \& Vaughan, N. D. (2008). Blended Learning In Higher Education : Framework, Principles, And Guidelines. Jossey-Bass.

Guo Fengru. (2019). Dysmenorrhea of Female College Students and Its Influence on Learning Engagement. Nursing Science, 08(02), 148-154. https://doi.org/10.12677/ns.2019.82029

He Kehang. (2004). On the educational ideas and philosophical foundations of constructivism. Expert Perspective, 71(3), 12-16.

He Lin, Wang Shuoyuan, Huang Wenjing, \& Wu Tong. (2020). Research on the application of blended teaching mode in teaching basic economic law in the background of Internet. Teaching Method Innovation and Practice, 3(10), 14. https://doi.org/10.26549/jxffcxysj.v3i10.5367

Heo, H., Bonk, C. J., \& Doo, M. Y. (2021). Enhancing learning engagement during COVID -19 pandemic: Self-efficacy in time management, technology use, and online learning environments. Journal of Computer Assisted Learning, 1-13. https://doi.org/10.1111/jcal.12603

Kuh, D. (2004). Childhood cognitive ability and deaths up until middle age: a post-war birth cohort study. International Journal of Epidemiology, 33(2), 408-413. https://doi.org/10.1093/ije/dyh043

Li Lu \& Li Minghua (2020). Analysis of factors influencing online learning power of college students. Journal of Zhejiang Normal University (Natural Science Edition), 43(3), 269-275.

Li Shuang \& Yu Chen (2015). Development and application of learning engagement evaluation scale for distance students. Open Education Research, 21(6), 62-70.

Liao Youguo (2011). The development of a questionnaire and a survey on the current situation of university students' learning engagement. Journal of Jimei University (Education Science Edition), 12(2), 39-44.

Newmann, F. M. (1992). Student engagement and achievement in American secondary schools. Teachers College Press.

Schaufeli, W. B., Salanova, M., González-romá, V., \& Bakker, A. B. (2002). The measurement of engagement and burnout: A two sample confirmatory factor analytic approach. Journal of Happiness Studies, 3(1), 7192. doi:10.1023/a:1015630930326

Shi Xiaocen. (2016). Diversified path of American K-12 blended learning revolution. Journal of Distance Education, 232(1).

Shi Xue \& Yang Xiaojuan (2020). A study on the factors influencing college students' online learning power in blended learning. Modern Educational Technology, 30(4), 95-100.

Skinner, E. A., Wellborn, J. G., \& Connell, J. P. (1990). What it takes to do well in school and whether I've got it: A process model of perceived control and children's engagement and achievement in school. Journal of Educational Psychology, 82(1), 22-32. https://doi.org/10.1037/0022-0663.82.1.22

Song Lingqing, Xu Lin \& Li Yaxuan (2020). Precision online teaching + home learning model: a way to improve students' learning quality during the epidemic. Chinese Electro-Chemical Education, 3, 114-122. 
Sun Hongmei, Yin Shanyan\&Wang Chunyan (2011). A study on the relationship between college students' learning engagement status and social support. Journal of Suihua College, 31(1), 41-43.

Sun Jiajia \& Gao Liwei. (2020). Reform of blended teaching mode based on rain classroom in the context of "Internet+." Computer Era, 9, 120-122. https://doi.org/10.16644/j.cnki.cn33-1094/tp.2020.09.032

Sun, J. C.-Y., \& Rueda, R. (2011). Situational interest, computer self-efficacy and selfregulation: Their impact on student engagement in distance education. British Journal of Educational Technology, 43(2), 191-204. https://doi.org/10.1111/j.1467-8535.2010.01157.x

Wang Meng. (2019). Research and practice of the blended teaching mode of "Interactive Media Design" under the background of "Internet+." Modern Education Forum, 1(2), 11-20. https://doi.org/10.32629/mef.v1i2.16

Wang Yashang (2013). An empirical study of university students' engagement in learning: an analysis based on data from the 2012 National Survey of University Students' Learning. China Higher Education Research, 1, 32-36.

Woltering, V., Herrler, A., Spitzer, K., \& Spreckelsen, C. (2009). Blended learning positively affects students' satisfaction and the role of the tutor in the problembased learning process: results of a mixed-method evaluation. Advances in Health Sciences Education, 14(5), 725-738. https://doi.org/10.1007/s10459-009-9154-6

$\mathrm{Xu}$ Kai \& Li Yannan. (2021). Factors influencing learning engagement of Chinese university students under the covid-19 pandemic : Focus on online learning. Journal of China Studies, 24(2), 65-81. https://doi.org/10.20288/jcs.2021.24.2.65

Ye Lixia. (2020). Practice and exploration of blended teaching of linear algebra based on Learning Pass and Dingding. Computer Era, 9, 106-108. https://doi.org/10.16644/j.cnki.cn33-1094/tp.2020.09.028

Yin Rui \& Xu Hanyun (2017). Modeling the structure of online learning inputs: An empirical analysis based on structural equation modeling. Open Education Research, 23(4), 101-111.

Yuan Zhihong. (2021). Research and Practice of Mixed Teaching Mode of Online Course-Taking the Advanced Mathematics Based on "Learning Pass + Ding Talk" as an Example. Creative Education Studies, 09(01), 221-226. https://doi.org/10.12677/ces.2021.91034

Zheng Qinhua \& Xu Junyan (2020). Online learning power: Structural characteristics and influencing factors. Open Education Research, 26(04), 77. 